\title{
Adequacy of Outpatient Specialty Care Access in Marketplace Plans Under the Affordable Care Act
}

\section{Citation}

Dorner, Stephen C., Douglas B. Jacobs, and Benjamin D. Sommers. 2015. "Adequacy of Outpatient Specialty Care Access in Marketplace Plans Under the Affordable Care Act." JAMA 314 (16) (October 27): 1749. doi:10.1001/jama.2015.9375.

\section{Published Version}

10.1001/jama.2015.9375

\section{Permanent link}

http://nrs.harvard.edu/urn-3:HUL.InstRepos:23606070

\section{Terms of Use}

This article was downloaded from Harvard University's DASH repository, and is made available under the terms and conditions applicable to Other Posted Material, as set forth at http:// nrs.harvard.edu/urn-3:HUL.InstRepos:dash.current.terms-of-use\#LAA

\section{Share Your Story}

The Harvard community has made this article openly available.

Please share how this access benefits you. Submit a story.

Accessibility 


\section{Letters}

\section{RESEARCH LETTER}

\section{Adequacy of Outpatient Specialty Care Access in Marketplace Plans Under the Affordable Care Act}

Nearly 12 million individuals have enrolled in coverage through the Affordable Care Act's insurance marketplaces. ${ }^{1}$ The US Department of Health and Human Services regulates plans, applying a "reasonable access" standard to ensure access to "a sufficient number and type of providers." ${ }^{2}$ Nonetheless, concerns remain about network adequacy. ${ }^{3}$ We assessed access to outpatient specialists in federal marketplace plans.

Methods | We examined physician networks in 34 states offering plans through the federal marketplace during 2015 open enrollment using the rating area (geographic unit for marketplace premiums) containing each state's most populous county. We analyzed 4 silver plans (the category of plans purchased by $69 \%$ of consumers) ${ }^{1}$ : lowest, second lowest, median, and highest premium plans. One plan was excluded for a defective search engine, yielding 135 plans.

Using plans' online directories between April 12 and 18, 2015, we searched for in-network specialist physicians in obstetrics/gynecology, dermatology, cardiology, psychiatry, oncology, and neurology (largest volume nonsurgical specialties) and endocrinology, rheumatology, and pulmonology (specialties treating common outpatient conditions). ${ }^{4}$ Accounting for patient travel, we applied a broad and narrow search radius relative to each rating area's most populous city. Based on directories' functionality, the broad radius was $160 \mathrm{~km}$ (100 miles) or, when unavailable (in 12\%), the maximum search radius (typically $80 \mathrm{~km}$ [50 miles]). Our narrow search was half the broad radius.
The primary outcome was whether plans included physicians in each specialty. We labeled plans without specialist physicians as specialist-deficient plans. We reassessed specialist-deficient plans 1 month later (May 14, 2015) and corroborated our findings by calling insurers directly. We analyzed the prevalence of specialist-deficient plans across premium levels using the $\chi^{2}$ test. We evaluated out-ofnetwork costs for these plans and compared monthly premiums for 40-year-old individuals in specialist-deficient plans with other plans using the $t$ test. Confidence intervals (95\%) were estimated in Stata (StataCorp) using the proportion command. A 2-sided $P$ value of $<.05$ was considered statistically significant.

Results | Using the broad and narrow searches, 18 (13.3\%; 95\% CI, 8.5\%-20.3\%) and 19 (14.1\%; 95\% CI, 9.1\%-21.1\%), respectively, of 135 plans were specialist-deficient plans. Two plans included dermatologists and oncologists in the broad search radius but not the narrow radius. Three plans included endocrinologists in the broad search radius but not the narrow radius.

Endocrinology, rheumatology, and psychiatry were most commonly excluded, and an additional 7-14 plans had fewer than 5 in-network physicians in those specialties (Table). There was no significant difference in the proportion of specialistdeficient plans across insurance plan premium levels $(P=.40)$.

Nine of 34 states (23.5\%; 95\% CI, $11.8 \%-41.5 \%$ ) had at least 1 specialist-deficient plan. Twelve different insurers had at least 1 specialist-deficient plan. Between assessments, 6 of 19 (31.6\%; 95\% CI, 13.7\%-57.3\%) specialist-deficient plans added specialists. Calls to the remaining plans confirmed the lack of innetwork physicians.

Table. In-Network Physicians by Specialty Within 160 km (100 Miles) ${ }^{a}$

\begin{tabular}{|c|c|c|c|c|}
\hline \multirow[b]{2}{*}{ Specialty } & \multicolumn{4}{|l|}{ No. (\%) $[95 \% \mathrm{Cl}]$} \\
\hline & $\begin{array}{l}\text { No. of Plans With } \\
0 \text { Specialists }\end{array}$ & $\begin{array}{l}\text { No. of Plans With } \\
1-2 \text { Specialists }\end{array}$ & $\begin{array}{l}\text { No. of Plans With } \\
\text { 3-5 Specialists }\end{array}$ & $\begin{array}{l}\text { No. of Plans With } \\
>5 \text { Specialists }\end{array}$ \\
\hline Cardiology & $1(0.7)[0.1-5.2]$ & $2(1.5)[0.4-5.8]$ & 0 & $132(97.8)[93.2-99.3]$ \\
\hline Dermatology & $4(3.0)[1.1-7.7]$ & $1(0.7)[0.1-5.2]$ & 0 & $130(96.3)$ [91.3-98.5] \\
\hline Endocrinology & $8(5.9)[3.0-11.5]$ & $3(2.2)[0.7-6.8]$ & $4(3.0)[1.1-7.7]$ & $120(88.9)[82.3-93.2]$ \\
\hline Neurology & $1(0.7)[0.1-5.2]$ & $2(1.5)[0.4-5.8]$ & $1(0.7)[0.1-5.2]$ & $131(97.0)$ [92.3-98.9] \\
\hline Obstetrics/gynecology & $2(1.5)[0.4-5.8]$ & 0 & 0 & 133 (98.5) [94.2-99.6] \\
\hline Oncology & $1(0.7)[0.1-5.2]$ & $2(1.5)[0.4-5.8]$ & $5(3.7)[1.5-8.7]$ & $127(94.1)$ [88.5-97.0] \\
\hline Psychiatry & $6(4.4)[2.0-9.6]$ & $2(1.5)[0.4-5.8]$ & 9 (6.7) [3.5-12.4] & $118(87.4)[80.6-92.1]$ \\
\hline Pulmonology & $1(0.7)[0.1-5.2]$ & $2(1.5)[0.4-5.8]$ & $8(5.9)$ [3.0-11.5] & $124(91.9)[85.8-95.5]$ \\
\hline Rheumatology & 9 (6.7) [3.4-12.4] & $5(3.7)[1.5-8.7]$ & $9(6.7)$ [3.5-12.4] & $112(83.0)[75.6-88.5]$ \\
\hline
\end{tabular}

The search radius was defined as $160 \mathrm{~km}$ for most plans (88\%). For the $12 \%$ of plans that did not offer that radius for their provider network search tool, we used the maximum available search radius (typically $80-120 \mathrm{~km}$ ). This study examined 135 plans in the silver tier on the federal marketplace in 2015 , representing the lowest, second lowest, median, and highest premium plans in each of the 34 federal marketplace states (excluding 1 plan whose search engine did not function correctly). Across each row, the percentages may not sum to $100 \%$ due to rounding. The $95 \%$ Cls were estimated in Stata using the proportion command. 
Beneficiaries of specialist-deficient plans had high outof-network costs; 5 of 19 (26.3\%; 95\% CI, 10.4\%-52.4\%) plans did not cover out-of-network services, whereas 11 of the remaining 14 plans (78.6\%; 95\% CI, 46.0\%-94.0\%) required cost-sharing of $50 \%$ or more. Nine of 19 (47.4\%; 95\% CI, 25.0\%-70.8\%) did not cover medications prescribed by out-of-network physicians. There was no significant difference in premiums between specialist-deficient plans (\$314; 95\% CI, \$254-\$375) and other plans (\$276; 95\% CI, $\$ 264-\$ 289 ; P=.21)$.

Discussion | In this study of federal marketplace plans, nearly $15 \%$ completely lacked in-network physicians for at least 1 specialty. We found this practice among multiple states and issuers. This likely violates network adequacy requirements, raising concerns regarding patient access to specialty care. Such plans precipitate high out-of-pocket costs and may lead to adverse selection (ie, sicker individuals choosing plans with broader networks), which is similar to concerns over restrictive drug formularies. ${ }^{5}$

We also found substantial turnover in directory listings. This may contribute to inaccuracies in listings, which prompted more stringent federal requirements for $2016 .{ }^{2}$ However, physician listings without any specialists (even if inaccurate) may confuse or impede consumers' access to physicians. Future research exploring this practice among different marketplace categories, as well as waiting times for in-network specialists, could provide additional insights.

This study has several limitations. We disproportionately analyzed lower cost plans due to their association with federal subsidies. Our study relied on physician directories, which may overestimate network breadth. ${ }^{6}$ We also focused on the largest population center in each state because rural regions are known to have fewer physicians and may have an even higher prevalence of specialist-deficient plans.

\section{Stephen C. Dorner, MSc \\ Douglas B. Jacobs, ScB \\ Benjamin D. Sommers, MD, PhD}

Author Affiliations: Department of Health Policy and Management, Harvard T. H. Chan School of Public Health, Boston, Massachusetts.

Corresponding Author: Stephen C. Dorner, MSc, Harvard T. H. Chan School of Public Health, 677 Huntington Ave, Boston, MA 02115 (stephen.dorner@post harvard.edu)

Author Contributions: Messrs Dorner and Jacobs had full access to all of the data in the study and take responsibility for the integrity of the data and the accuracy of the data analysis.

Study concept and design: All authors.

Acquisition, analysis, or interpretation of data: All authors.

Drafting of the manuscript: Dorner, Jacobs.

Critical revision of the manuscript for important intellectual content: All authors. Statistical analysis: All authors.

Administrative, technical, or material support: Dorner, Sommers.

Study supervision: Dorner, Sommers.

Conflict of Interest Disclosures: The authors have completed and submitted the ICMJE Form for Disclosure of Potential Conflicts of Interest. Dr Sommers reported currently serving part-time as a senior advisor to the US Department of Health and Human Services. No other disclosures were reported.

Disclaimer: This work does not represent the views of the US Department of Health and Human Services.
1. US Department of Health and Human Services. Health insurance marketplaces 2015 open enrollment period: March enrollment report. http://aspe.hhs.gov/health/reports/2015/MarketPlaceEnrollment/Mar2015/ib 2015mar_enrollment.pdf. Accessed May 3, 2015.

2. US Department of Health and Human Services. Final 2016 letter to issuers in the federally-facilitated marketplaces. http://www.cms.gov/CCIIO/Resources /Regulations-and-Guidance/Downloads/2016_Letter_to_Issuers_2_20_2015.pdf. Accessed March 7, 2015.

3. Haeder SF, Weimer DL, Mukamel DB. California hospital networks are narrower in Marketplace than in commercial plans, but access and quality are similar. Health Aff (Millwood). 2015;34(5):741-748.

4. Centers for Disease Control and Prevention; National Center for Health Statistics. National Ambulatory Medical Care Survey: 2010 summary tables. http://www.cdc.gov/nchs/data/ahcd/namcs_summary/2010_namcs_web_tables .pdf. Accessed April 3, 2015

5. Jacobs DB, Sommers BD. Using drugs to discriminate-adverse selection in the insurance marketplace. N Engl J Med. 2015;372(5):399-402.

6. Resneck JS Jr, Quiggle A, Liu M, Brewster DW. The accuracy of dermatology network physician directories posted by Medicare Advantage health plans in an era of narrow networks. JAMA Dermatol. 2014;150(12):1290-1297.

\section{COMMENT \& RESPONSE}

\section{Medical Use of Cannabinoids}

To the Editor Dr Whiting and colleagues presented a systematic review of medical cannabinoids. ${ }^{1}$ The University of California Center for Medicinal Cannabis Research has conducted 5 placebo-controlled clinical trials with smoked or inhaled cannabis for neuropathic pain, representing, to my knowledge, the only studies approved by the US Department of Health and Human Services to be conducted in the United States during the past 2 decades.

However, Whiting and colleagues only considered 1 of these studies. The studies that were not in the final analysis included 2 on smoked marijuana of varying tetrahydrocannabinol (THC) concentrations ${ }^{2,3}$ and 2 on vaporized cannabis. ${ }^{4,5}$

The results of these 4 studies reinforce the likely efficacy of cannabis in neuropathic pain, but with an important added observation: benefit was noted at low THC concentrations ( $<4 \%)$. This has clinical importance, suggesting therapeutic benefit of cannabis with THC content that is less likely to produce undesirable behavioral or neurocognitive adverse effects (ie, an improved safety profile).

In addition, the latter 2 studies support vaporized cannabis as an alternative to smoking. All these studies indicate benefit from inhaled cannabis, which is relevant given that many patients will continue to favor this mode.

\section{Igor Grant, MD}

Author Affiliation: University of California Center for Medicinal Cannabis Research, University of California San Diego, La Jolla.

Corresponding Author: Igor Grant, MD, University of California Center for Medicinal Cannabis Research, University of California San Diego, Department of Psychiatry, 9500 Gilman Dr, La Jolla, CA 92093 (igrant@ucsd.edu).

Conflict of Interest Disclosures: The author has completed and submitted the ICMJE Form for Disclosure of Potential Conflicts of Interest and none were reported.

1. Whiting PF, Wolff RF, Deshpande $S$, et al. Cannabinoids for medical use: a systematic review and meta-analysis. JAMA. 2015;313(24):2456-2473. 